\title{
ESPECIAL
}

\section{A pesquisa administrativa e a ENAP}

\author{
Florindo Villa-Alvarez*
}

A

ENAP deverá ser o laboratório administrativo do exercício democrático e da prática participativa de negociação e compromisso em formular, implementar e avaliar as políticas públicas de um novo Estado de Direito, buscando formar o Gestor Governamental.

A transição democrática brasileira, ainda frágil, tem de ser conscientemente administrada como a transição de vinte anos de arbítrio militar para a implantação de uma democracia plena, centrada na historicidade brasileira e em uma nova constituição que seja, no dizer de Tancredo Neves, "uma Carla de Compromissos assumidos livremente pelos cidadãos" (o grifo é nosso).

A atual tarefa da Assembléia Constituinte é a primeira etapa, e a fundamental, em que se alicerça a transição, mas a segunda e próxima etapa, aquela que os futuros egressos gestores governamentais da ENAP terão de administrar, será a de implementar e sedimentar os alicerces de uma democracia plena, isto é, a etapa da institucionalização democrática do Brasil.

\section{PESQUISA ADMINISTRATIVA}

Pesquisa Administrativa, como função permanente do sistema e subsistemas administrativos, a par das demais funções administrativas, é um procedimento racional e contínuo de avaliação e controle de todo processo administrativo, a par de gerador de conhecimento:

- "a priori", ou de início, como subsidio essencial ao planejamento estratégico administrativo e à análise da estrutura organizacional administrativa;

- durante, ou ao longo do fluxo de operacionalização administrativa, isto é, como acompanhamento avaliativo de todo o processo administrativo; e

- "a posteriori", ou ao final de um determinado procedimento administrativo, inserido no contexto global de todo o processo administrativo, isto é, como avaliação e con-

- Professor de Pesquisa da Universidade Federal Fluminense e atualmente, Diretor de Ensino e Pesquisa da ENAP. trole de resultados ou consecução de predeterminados objetivos, e cujos resultados passam a retroalimentar o fluxo geral do sistema e subsistemas administrativos, através, sobretudo, do processo decisório da gestão administrativa, ou do saber e do fazer administrativos.

A pesquisa em administração seria a produzida por qualquer pessoa ou instituição social que deseje repensar, questionar, investigar, o saber e o fazer administrativos, com o objetivo precípuo de conhecer e de explicar a ciência ou arte de administrar, e sem necessariamente pretender avaliar e controlar, internamente, como administrador, o sistema e subsistemas administrativos.

Há diferentes metodologias e técnicas de pesquisas, em decorrência das várias abordagens epistemológicas do conhecimento humano.

O procedimento metodológico fundamental do processo de pesquisar consiste em:

- quantificar dados de informação;

- qualificar dados de informação;

- comparar e correlacionar esses dados, com objetivo de ampliar os níveis de crescente explicação científica, através de diversos métodos e técnicas de quantificação de dados da informação, a qual é a matériaprima que alimenta o fluxo dos sistemas e subsistemas de conhecimento humano, em particular do conhecimento administrativo, sempre dialeticamente caracterizado como o saber e o fazer administrativos.

Este processo dispõe de métodos de pesquisa, tais como:

- descritivo;

- observação sistemática;

- histórico-comparativo;

- analógico;

- análise de conteúdo;

- indutivo;

- dedutivo;

— hipotético-dedutivo;

— dialético;

- estudo de caso;

- avaliativo e de controle, da pesquisa de ação (ou "pesquisa-ação");

- pesquisa participante ou participativa, ou associativa;
- pesquisa operacional;

- depoimento histórico (história oral) etc.

Técnicas instrumentais de mensuração em pesquisa, tais como:

- estatísticas (paramétricas e não-paramétricas) tais como ponderações, médias, modas, medianas, amostragem, escalagem (escalas), entre outras;

- técnicas de coleta de dados: entrevistas e questionários;

- técnicas de fluxos: fluxogramas, organogramas, cronogramas; PERT (tempo e custo);

- técnicas de codificação de dados; tábuas, quadros, gráficos, etc.;

- jogos;

- simulações, etc.

Os métodos de estudos de casos e a produção de dossiês são resultados de processos de pesquisa. Ambos métodos se iniciam pela técnica de levantamento de dados, que é o ponto de partida da técnica de diagnóstico.

A Administração da pesquisa, que consiste na própria gestão administrativa do processo de pesquisar, é feita por projetos ou por administração matricial.

"Matricial" é a administração que privilegia "matrizes" ou projetos administrativos em contraposição ao enfoque funcional ou por funções administrativas.

Pesquisa básica em administração seria aquela devotada à teoria das organizaçōes ou teoria das estruturas organizacionais administrativas, ou de produção do conhecimento administrativo.

Pesquisa aplicada em administração seria aquela especificamente voltada para os setores organizacionais nos quais a administração é aplicada.

Dossiê é um conjunto de documentos referentes a um órgão, fato ou problema específico e que serve para informar e contextualizar parecer técnico, tomada de decisão, medida administrativa e legal ou simplesmente posicionamento face à questão.

A pesquisa administrativa deverá ser o cerne dos procedimentos gerenciais, nos quais deverá centrar-se a prática administrativa, através de projetos de pesquisa tais como os de estudos de casos, dossiês, seminários, "laboratórios" ou "oficinas", jogos e simulaçōes computadorizadas, lei- 


\section{ESPECIAL}

turas orientadas para a discussāo em grupos, dinâmica de grupo, entre outros, como parte dos métodos e técnicas de pesquisa participativa ou pesquisa de ação (pesquisa-ação).

Projetos individuais e grupais de pesquisas administrativas deverão ser desenvolvidos em função de tópicos e linhas de pesquisas em administração pública, ressaltando a pesquisa de ação (ou "pesquisa-ação"), como uma das técnicas de pesquisa participativa, ou participante, aplicada à identificação, resolução e avaliação de problemas específicos de administração pública.

Todas as pesquisas administrativas devem ser calcadas em atividades práticas e aplicadas, e em projetos de pesquisas institucionais, desenvolvidas pela própria administração, com ou sem a utilização de consultoria externa à instituição.

Os resultados e relatórios finais dessas atividades práticas e desses projetos de pesquisas serão fundamentais aos critérios de avaliação de desempenho da administração.

Ênfase em pesquisa aplicada à problemática da administração pública, sem excluir excepcionais projetos de alto nivel teórico e científico da pesquisa básica.

A pesquisa deverá estar apoiada em exaustiva documentação e em bibliografias especializadas, e no processamento de dados da informática, através de "pacotes" do tipo SPSS (Statistical Package for Social Sciences) ou do SAS, e dos Sistemas de Informaçōes Gerenciais (SIG's).

Linhas de pesquisa deverão ser definidas - prioritárias e relevantes - em função da problemática da administração pública.

Assegurar eficaz acompanhamento à elaboração, immplementação e avaliação dos projetos de pesquisas, engajando todos os funcionários, e especialistas, se os houver, de reconhecida competência profissional em pesquisa.

Cumpre ressaltar que todo trabalho de manipulação da informação a ser processada pela informatização já é, em si mesmo, um trabalho de pesquisa documental.

Por isso mesmo não se pode prescindir do processo de pesquisa prévia de informação, ao se elaborarem, por exemplo, formulários, ou ao se mecanizar a informação destinada ao processo de informatização. Em suma, já não se pode administrar, sem pesquisa.

Desde 1951, com a criação da EBAP, no Rio, pela Fundação Getúlio Vargas FGV; da EAESP, em São Paulo, e da EIAP, no Rio, também da FGV, (dessas

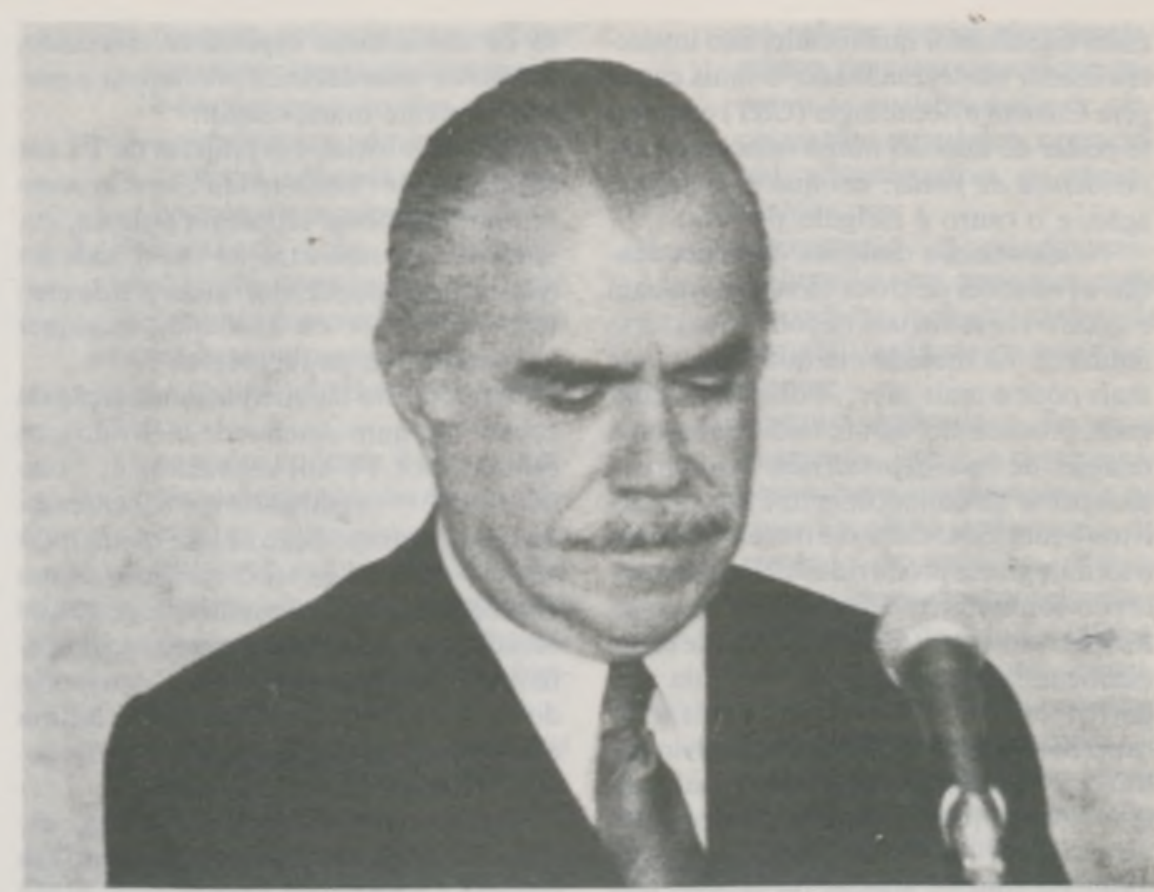

três Escolas, fomos um dos fundadores) ao longo, pois desses últimos 30 anos vimos expandir-se, por todo o Brasil, um ensino de administração, informativo e repetitivo, com muito pouca imaginação e criatividade, praticamente sem pesquisa em administração, sem questionamentos profundos às teorias e práticas da estrutura organizacional do desenvolvimento institucional brasileiro.

As frustradas Reformas Administrativas e o desordenado crescimento empresarial aí está para atestar quão pouca racionalidade administrativa e quanta improvisação, ratificando ou validando essa asserção melancólica.

Pouco se tem feito por tornar a ciência da administração mais cientifica, em que pese o aparente cientificismo de sua roupagem.

A par de muito ensino e muito pouca pesquisa, os "especialistas" em administração se esforçam por fazer clinica geral ou especializada, e esporádica, em administração, como consultores, cuja consultoria assistencialista e/ou de "arrumação da casa" consegue fazer bons diagnósticos, prognoses e posologias, cujas dosagens intermitentes, dificilmente logram a cura da improvisação institucional, da qual os consultores se tornam mais objeto do que sujeito da ação, ou, em paráfrase pessoal nossa, a Paulo Freire, mais cavalos, do que cavaleiros das decisões e ações administrativas. Parece que os administradores ainda não conseguiram comandar o processo de mudança adminis- trativa, pois não estão a cavaleiro da ciência da administração, desgastada em procedimentos instrumentalistas, subservientes das estruturas de poder. Quando muito, o ensino da administração produziu eminentes tecnocratas ou tecnoburocratas, enebriados com a co-participação no exercício do poder político-administrativo, a que se associam como um tipo de gerentecapataz.

Esse gerente-capataz conhece as regras do jogo e as aceita e manipula, porque participa do jogo, mas sobretudo como um repassador da bola, com muito pouca ou nenhuma influência sobre as estratégias e táticas da composição da estrutura e do exercício do poder.

\section{Da Gestão Tecnológica \\ (P. \& D. em C \& T.)}

\section{- Da Relação Dialética Pesquisador - Pesquisado}

Há uma relação dialética entre o pesquisador e o objeto da pesquisa - pessoa ou coisa pesquisada - e ambos são partes integrantes do processo de desenvolvimento científico e tecnológico. Não se trata, porém, de uma relaçâo de dependência, mas de interdependência, na qual ambas partes se devem engajar, numa interação em que ambos são, ao mesmo tempo, sujeito e objeto da ação.

Na relaçâo dialética alta-renda/baixarenda, ou entre analfabeto/alfabetizado, iletrado/letrado, trabalhador não qualifi- 
cado/trabalhador qualificado, não intelectualizado/intelectualizado, o mais capaz gera Ciência e Tecnologia (C\&T) e adquire poder de decisão numa relação de dependência de poder, em que um dirige a ação, e o outro é dirigido por ela.

Nessa relação dialética de dependência, as relações de troca só se humanizam e as diferenças sociais e econômicas só se reduzem, na medida em que aquele que mais pode e mais sabe, se disponha a dar mais, procurando, assim, restabelecer uma relação de interdependência eqüitativa, somatória do conhecimento e dos respectivos benefícios, cada vez mais científicos e tecnológicos, produzidos pelos detentores do conhecimento científico. $E$ se aqueles que transferem tecnologia não se conscientizam dessa filosofia de vida coparticipativa e colaborativa, jamais se alcançará a plenitude de um desenvolvimento sócio-econômico aquânime, realmente justo, em que o problema de distribuição e redistribuição de renda não se coloque em função, apenas, da variável renda.

A "filosofia" por trás da - Transferência de Tecnologia - TT - consiste, pois, na tomada da consciência dessa relação dialética pesquisador-pesquisado, engajando e integrando, a ambos, numa relação somatória de dar e receber mútuo, em que a percepção valorativa de cada um, não subordine o menos capaz ao mais capaz, admitindo, transitoriamente, valores diferenciados, sim, mas não utilizando essa diferenciação como justificativa para perpetuar uma relação de dominação.

No Sistema de Economia de Mercado, de uma sociedade de consumo, a correção de contradições e distorçōes e, conseqüentemente, a evolução do próprio sistema se faz pela conscientização de um processo permanente e contínuo de reflexão crítica e de autocorreção desse sistema.

Cumpre, porém, ressaltar a validade relativa da opção de conviver com esse sistema aberto, contraditório, e, muitas vezes, incoerente, do sistema de economia de mercado, cujas relaçôes de troca são desiguais, porém sempre aberto a negociações, em contraposição a um sistema teoricamente equalitário, mas, de fato, na prática, autocrático, em que apenas a minoria dos detentores do poder, impõe à maioria, vontades e decisões inquestionáveis, intransigentes e intolerantes ao diálogo.

Essa validade relativa de opção é mais difícil de ser operacionalizada no contex- to de um sistema capitalista associado, imitativo, retardatário, predatório e prevalentemente manipulador.

A ênfase social, em projetos de TT aos segmentos de "baixa renda", se vem constituindo em óbvia estratégia política, cujo efeito - demonstração tanto pode ser o de efeito multiplicador, quanto o de efeito manipulador ou alienador, qualquer que seja a "carga ideológica".

No contexto da internacionalização da economia, num sistema de mercados, os esforços por TT aos segmentos de "baixa renda" - implicitamente subentendidos, em contraposição aos de renda mais altas - não podem ser dissociados de um contexto mais complexo dos processos de socialização, educação e capacitação profissional desses segmentos, cuja melhoria do nivel de renda está em relação íntima e direta com outros níveis de melhoria: social, educacional, profissional.

É dentro desse referencial teórico, es. sencial à Pesquisa e Desenvolvimento em Ciência e Tecnologia, que se deve situar a Gestão Tecnológica, cuja eficácia depende de uma Ciência de Administração, tanto mais científica, quanto mais profunda for a sua praxis, amadurecida no exercicio teórico-prático de administrar ou gerir as estruturas organizacionais de poder governamental e empresarial.

E cabe ao nível de pós-graduação em administração, uma parcela dessa tarefa de administrar ou gerir pessoas, processos e instituições, no contexto do desenvolvimento institucional.

Sem provincianismos regionais, mas percebidas as Regiões Norte e Nordeste e Centro-Oeste em relação dialética com as demais regiōes do pais, especialmente com a Região Centro-Sul do Brasil, a pósgraduação em administração deve saber pesquisar e desenvolver, com visão de mundo - teorias e práticas de explicar e instrumentalizar a ciência da decisão e da ação administrativas.

A Ciência da Administração é uma das ciências factuais, responsáveis pelo desenvolvimento institucional das instituições sociais. Sua lógica formal e sua lógica dialética se devem conjugar e concentrar na correlação dinâmica e auto-reguladora de decisão-ação, avaliadas e reavaliadas, continuamente, questionadas e requestionadas sempre.

A intervenção deliberada e racional do administrador, no processo políticoadministrativo de decidir e de gerir, tanto pode fazer dele um líder da crescente co-participação administrativa, quanto pode transformá-lo num arrogante e au- tocrático manipulador de pessoas, procedimentos e instituições sociais, como é freqüente entre os tecnocratas prepotentes e auto-suficientes, em todas as estruturas de poder, das mais diversas colorações ideológicas.

Um dos riscos que comprometem o desenvolvimento institucional é o do açodamento com que a liderança afoita se apressa em assumir e manipular o poder, sem a capacidade aliciadora de envolver e engajar o maior número e a maior diversidade de pessoas, aglutinando os mais e os menos capazes, num esforço por amalgamar grupos humanos heterogêneos, cujas capacitações e limitações básicas não são como gostaríamos que fossem - uma realidade concreta em si mesma - , porém potencialmente capaz de ser desenvolvida e ampliada em eficácia, se, realmente, soubermos desenvolver uma administração co-participativa por equipes, do tipo "matricial".

A tarefa inicial, complexa e difícil, consiste, sempre, em provocar estímulos que levem as pessoas a dar respostas, a se envolver e se engajar e assumir parcelas de decisão e de ação administrativas, num contexto coerente e coeso de trabalho em equipe, concentrado em projetos, mais do que em funções.

O curioso é que, às vezes, alguns líderes inteligentes e capazes assumem a liderança verbal da gestão administrativa, mas têm dificuldade em assumir a liderança da decisão-ação, por motivos os mais diversos, os mais defensáveis e indefensáveis.

$\mathrm{O}$ administrador que decide e que age é algo assim como um jogador de um jogo solitário ou de um "quebra-cabeça", cuja solução depende da interdependência de peças ou partes de diferentes tamanhos e formas. Descobri-las em seus contornos e ajustá-las à coerência do todo, eis a chave do jogo.

Sugestōes de Linhas de Pesquisa em Administração

I - Pesquisa pura ou básica (ou de elaboração de teorias)

1. Objetivo - formação e ampliação de um Corpus Teórico, a fim de definir e delimitar a Ciência $d a A d$ ministração, fortalecendo a natureza instrumental, mediadora e integradora dessa ciência; caracterizar melhor a natureza multidisciplinar da ciência da administração. 


\section{ESPECIAL}

2. Sugestões de linhas e tópicos de pesquisa:

a) origem e historicidade da gestão administrativa, como estrutura organizacional da gestão de existir e da formação de conhecimento científico-tecnológico; origem e história da administração brasileira;

b) teoria dos sistemas, sistemas e subsistemas de relações;

c) teoria das organizações;

d) estruturalismo, funcionalismo e administração;

e) racionalidade, controle e administração;

f) lógica dialética e lógica formal aplicadas à pesquisa em administração;

g) pesquisa e desenvolvimento, em ciência e tecnologia (P \& D em C \& T) e gestāo tecnológica.

\section{II - Pesquisa aplicada (ou empírica)}

1. Hipotético-dedutiva, para validar ou refutar, a aplicação, na prática administrativa, de teorias da ciência da administração:

a) pesquisa aplicada às funçōes administrativas, para validar ou refutar a asserção teórica de que: todos as funções administrativas são funçōes de controle, as quais constituem um sistema integrado de controles administrativos; b) pesquisa aplicada, para validar ou refutar teorias da informação e da comunicação, dos sistemas e.subsistemas administrativos;

c) pesquisa aplicada ao processo decisório em administração.

2. Pesquisa de ação ou pesquisaintervenção, considerando a função da pesquisa como atividade permanente de acompanhamento, avaliação e controle do fluxo administrativo:

a) pesquisa aplicada à reestruturação e reorganização de procedimentos administrativos, em quaisquer casos de aplicação da ciência da administração às áreas: de trabalho, lazer, hospitalar, hoteleira, desportiva, bancária, etc.;

b) pesquisa aplicada às estruturas organizacionais especificas: a governamental (civil, militar, federal, estadual, municipal, e/ou local), a empresarial de negócios, em termos, por exemplo, de mensuração de eficiência e eficácia do processo empresarial brasileiro, tais como: origem e desenvolvimento do empresarialismo brasileiro, endividamento do empresarialismo brasileiro, endividamento e sobrevivência das empresas brasileiras;

c) pesquisa aplicada, para validar ou refutar teorias do planejamento, em casos especificos, tais como os institucionais, de planejamento estratégico, operacional, administrativo, de investimentos, etc;

d) mensuração da relação custo/benefício em quaisquer casos específicos, inclusive na área de contabilização de recursos humanos;

e) pesquisa aplicada a Recursos Humanos, isto é, a determinadas estruturas ocupacionais, no jogo de oferta e demanda do mercado de trabalho, relacionando: formação, capacitação e qualificação de recursos humanos, ou de mão-de-obra, em geral, ao mercado de trabalho, num sistema de economia de mercado, e no contexto de um sistema capitalista associado, imitativo e retardatário;

f) pesquisa aplicada à logistica de materiais, em casos administrativos específicos;

g) pesquisa aplicada à análise e avaliação de instrumentos e procedimentos financeiros, em função de determinadas políticas fínanceiras.

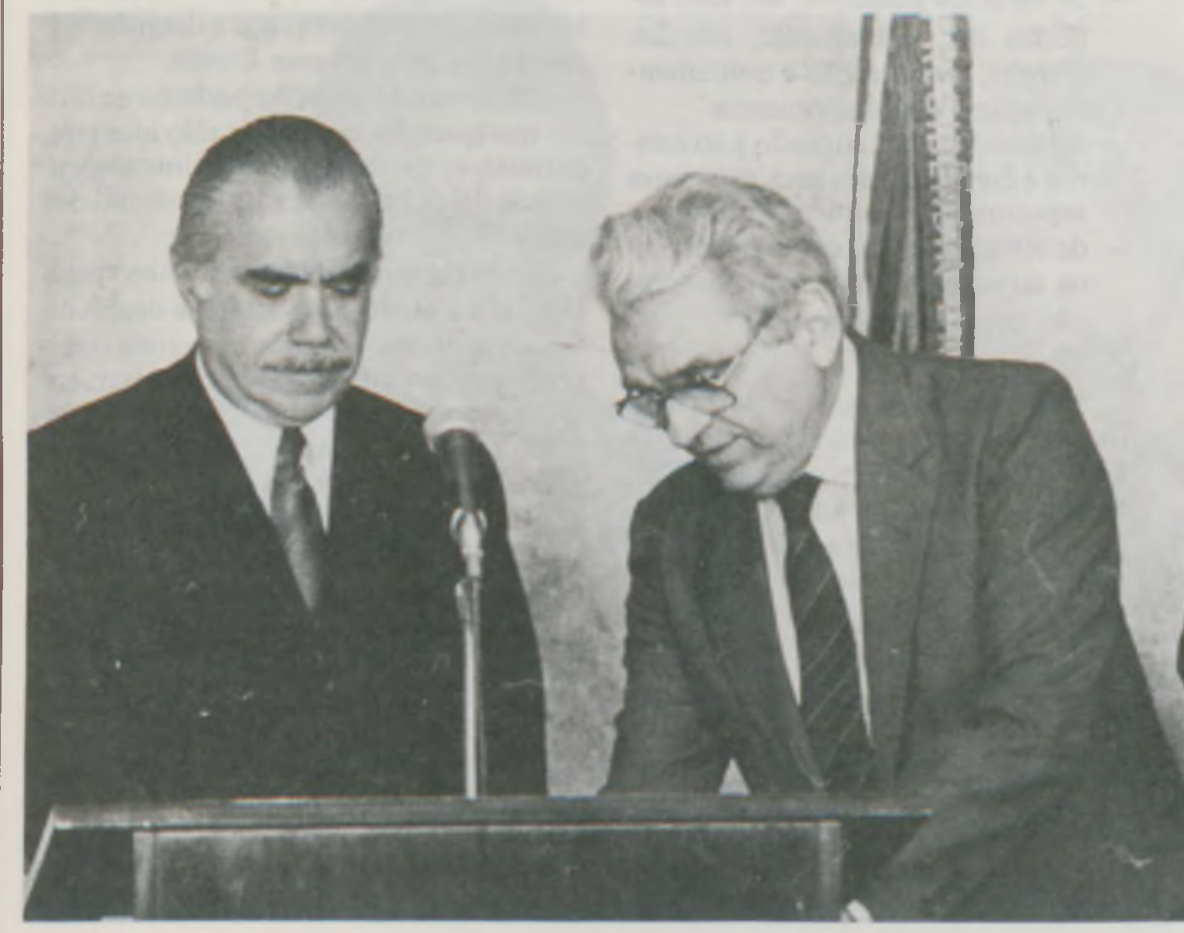

